\title{
Single and Multiple Level One Stage Posterior Hemivertebrectomy and Short Segment Fixation: Experience with 22 Cases and Comparison of Single vs. Multilevel Procedures with Minimum 2-Year Follow-Up
}

Saumyajit Basu, Agnivesh Tikoo, Farid H. Malik, Jay Deep Ghosh, Mantu Jain, Trinanjan Sarangi

Department of Neurosciences, Park Clinic, Kolkata, India

Study Design: Data of 22 patients with congenital scoliosis who underwent single stage posterior hemivertebrectomies and short segment fixation with a minimum follow-up of 2 years in our centre were studied retrospectively.

Purpose: To report the efficacy of posterior hemivertebrectomy in single vs multiple level hemivertebra and compare their results. Overview of Literature: Single stage hemivertebrectomy is a standard procedure for single level hemivertebra. Results of multiple level hemivertebrectomies have not been reported.

Methods: Twenty-two patients ( 9 male and 13 female) with the mean age of 11.2 years (range, 2 years 4 months to 24 years 10 months) and a mean follow up of 32 months (range, 4 to 73 months) were studied retrospectively and their results were compared.

Results: Average number of hemivertebrae removed was 1.46 (range, 1 to 3). Mean preoperative and postoperative coronal cob angle was $48.7^{\circ}$ (range, $22^{\circ}$ to $80^{\circ}$ ) and $24.2^{\circ}$ (range, $7^{\circ}$ to $41^{\circ}$ ), respectively $(p<0.001$ ). Mean preoperative and postoperative sagittal cobb angle was $32.1^{\circ}$ (range, $7^{\circ}$ to $76^{\circ}$ ) and $13.6^{\circ}$ (range, $0^{\circ}$ to $23^{\circ}$ ), respectively $(p<0.005$ ). Mean coronal and sagittal cob correction percentage achieved was $50.2 \%$ and $51.8 \%$ respectively. Mean follow-up was 49 months (range, 30 to 84 months). Mean loss of coronal and sagittal correction at final follow-up was $4 \%(0 \%$ to $13.6 \%$ ) degrees and $3.5 \%(0 \%$ to $20 \%)$, respectively.

Conclusions: Posterior hemivertebrectomy in congenital scoliosis is a safe treatment option for up to 3-level hemivertebrae. Excision of thoracolumbar hemivertebrae results in better correction than thoracic and lumbar hemivertebrae.

Keywords: Scoliosis; Spine; Congenital abnormalities; Kyphosis; Spinal curvatures

\section{Introduction}

Congenital defects usually have serious consequences in spinal growth. The severity of the congenital deformity depends on the type of anomaly, the site at which it occurred, and the overall growth potential of the individual. Without any treatment $85 \%$ of the patients will have spinal curves exceeding 41 degrees [1]. The non-surgical

Received Aug 23, 2015; Revised Oct 7, 2015; Accepted Oct 9, 2015

Corresponding author: Agnivesh Tikoo

Department of Neurosciences, Park Clinic, 4 Gorky Terrace, Minto Park, Kolkata 700017 India

Tel: +91-33-4019-9000, Fax: +91-33-2280-1807, E-mail: agniveshtikoo@gmail.com 
treatment is rarely successful. Seventy five percent of the curves are progressive and only 5 to $10 \%$ can be treated with bracing [2]. Winter studied the natural history and progression of congenital scoliosis on 234 patients and also classified them $[3,4]$. The classification was further modified and elaborated by McMaster, where the congenital vertebral anomalies were classified into four types (type I to III and unclassified) [5]. Hemivertebra excision is a safe and effective procedure for congenital scoliosis and results are better with early surgery [6,7]. However, results of multi-level hemivertebrectomies have not been reported. The present retrospective analysis assessed the outcome of 22 patients with congenital kyphoscoliosis who underwent one-stage posterior resection and short segment pedicle screw fixation in our centre.

\section{Materials and Methods}

Data of the 22 patients who underwent a single stage posterior hemivertebra resection and transpedicular fixation with a minimum two-year follow-up were analysed retrospectively (Table 1 ). There were nine male and 13 female patients. The mean age was 11.2 years (range, 2 years 4 months to 24 years 10 months). All the patients were evaluated with AP and lateral X-rays, computed tomography (CT) and magnetic resonance imaging (MRI) of the spine, and had been screened for associated congenital anomalies. 15 of 22 patients (68.2\%) had pure failure of formation (type I anomaly) [5] while three were type III and four were type IV. Three of the 15 type I anomaly patients had two segmented hemivertebrae at two levels and one patient had three hemivertebrae (two segmented and one semi segmented), for a total of 20 hemivertebrae. Of these 20, 14 were segmented vertebrae and six were semi-segmented (Table 1). Among the remaining seven patients $(31.8 \%)$, three $(13.6 \%)$ had mixed (type III) defects (anterolateral bar associated with posterolateral hemivertebrae) and four (18.2\%) had unclassifiable anomalies (type IV). None of the patients having type II defect required surgery. Of the 22 patients, two (9\%) had associated foot/leg weakness and calf muscle atrophy. They had equino-varus deformity that was surgically corrected by a paediatric orthopaedic surgeon. Four patients (18.1\%) had other congenital anomalies that included rectovaginal fistula and tethered cord, rectovestibular fistula, ileal atresia, and Tetrology of Fallot's in one case each (Table 1).

\section{Surgical technique}

All the patients were operated with neurophysiological monitoring. Pedicle screw and rod construct was used in all cases. The pedicle screws were placed followed by transpedicular decancellation of the anomalous vertebra(e). Complete excision of hemivertebra was done while a temporary rod held the construct on the concave. This was followed by a gradual controlled compression on the convexity to achieve coronal and sagittal correction (Figs. 1, 2). Local bone was used for posterior/ posterolateral fusion. Patients were mobilized out of bed from the day 3 following surgery. The mean number of hemivertebrae/anomalous vertebrae removed was 1.46 (range, 1 to 3 ). All the patients were braced postoperatively for 12 weeks. The mean follow-up was 49 months (range, 30 to 84 months).

\section{Results}

The mean operating time was 300 minutes (range, 150 to 400 minutes). The mean blood loss during the surgery was $611 \mathrm{~mL}$ (range, 200 to $1,300 \mathrm{~mL}$ ). The mean duration of hospital stay was 10.4 days (range, 6 to 15 days).

\section{Coronal correction}

The mean preoperative coronal main curve cobb angle was $48.7^{\circ}$ (range, $22^{\circ}$ to $80^{\circ}$ ), which was corrected to a mean of $24.2^{\circ}$ (range, $7^{\circ}$ to $41^{\circ}$ ) postoperatively giving a mean correction of $24.5^{\circ}$ or $50.3 \%$. The mean coronal cobb angle at the final follow-up was $26.2^{\circ}$ (range, $10^{\circ}$ to $47^{\circ}$ ). The mean loss of correction between the immediate postoperative period and final follow-up was $2^{\circ}$ (range, $0^{\circ}$ to $8^{\circ}$ ).

\section{Sagittal correction}

The mean preoperative sagittal main curve angle was $32.1^{\circ}$ (range, $7^{\circ}$ to $76^{\circ}$ ), which was corrected to a mean of $13.6^{\circ}$ (range, $0^{\circ}$ to $23^{\circ}$ ) immediately postoperatively giving a mean correction of $18.5^{\circ}$ (range, $3^{\circ}$ to $40^{\circ}$ ) or $51.8 \%$ (range, $0 \%$ to $100 \%)$. The mean sagittal cobb angle at the final follow-up was $14.8^{\circ}$ (range, $0^{\circ}$ to $40^{\circ}$ ). The mean loss of correction between the immediate postoperative period and final follow-up was $1.2^{\circ}$ (range, $0^{\circ}$ to $9^{\circ}$ ) or $3.5 \%$ (range, $0 \%$ to $20 \%$ ).

Maximum correction in both coronal and sagittal 
Table 1. Case details

\begin{tabular}{|c|c|c|c|c|c|c|c|c|c|}
\hline S. No. & Age & Sex & Level & Side & $\begin{array}{c}\text { No. of } \\
\text { hemivertebrae }\end{array}$ & & Type & $\begin{array}{l}\text { Associated } \\
\text { anomalies }\end{array}$ & $\begin{array}{l}\text { Neurological } \\
\text { status }\end{array}$ \\
\hline 1 & 2 yr $4 \mathrm{mo}$ & Male & D11 & L & 1 & 1 & Segmented & Ileal atresia & Nil \\
\hline 2 & 4 yr 3 mo & Female & $\mathrm{D} 4,5,6$ & L & 3 & IV & $\begin{array}{c}\text { Multiple } \\
\text { hemivertebrae }\end{array}$ & Nil & Nil \\
\hline 3 & 4 yr 7 mo & Female & L5 & $\mathrm{R}$ & 1 & 1 & Segmented & $\begin{array}{l}\text { Recto vaginal } \\
\text { fistula, tethered } \\
\text { cord, }\end{array}$ & $\begin{array}{l}\text { L calf atrophy, } \\
\text { equino varus I } \\
\text { foot }\end{array}$ \\
\hline 4 & 17 yr 4 mo & Female & L1 & L & 1 & III & $\begin{array}{l}\text { Segmented with } \\
\text { concave bar }\end{array}$ & Nil & $\begin{array}{c}\text { Foot weakness, } \\
\text { equino varus } \\
\text { deformity }\end{array}$ \\
\hline 5 & 13 yr 9 mo & Male & $\mathrm{D} 6,8,10$ & $\mathrm{R}$ & 3 & 1 & $\begin{array}{c}\text { Segmented, } \\
\text { Semi segmented }\end{array}$ & Nil & Nil \\
\hline 6 & 13 yr $11 \mathrm{mo}$ & Male & L2 & $\mathrm{R}$ & 1 & III & $\begin{array}{l}\text { Segmented with } \\
\text { concave bar }\end{array}$ & $\begin{array}{c}\text { Delayed milestones, } \\
\text { congenital ear } \\
\text { (pinna) anomalies }\end{array}$ & Nil \\
\hline 7 & 10 yr 2 mo & Female & D12,L1 & L & 2 & IV & $\begin{array}{c}\text { Multiple } \\
\text { hemivertebrae }\end{array}$ & Nil & $\mathrm{Nil}$ \\
\hline 8 & 4 yr 6 mo & Female & $\mathrm{D} 7,9$ & $\mathrm{R}$ & 2 & 1 & Segmented & Nil & Nil \\
\hline 9 & 3 yr 8 mo & Female & $\mathrm{D} 2,3$ & $\mathrm{R}$ & 2 & IV & $\begin{array}{c}\text { Multiple } \\
\text { hemivertebrae }\end{array}$ & $\begin{array}{l}\text { Rectovestibular } \\
\text { fistula }\end{array}$ & Nil \\
\hline 10 & 13 yr 3 mo & Male & $\begin{array}{l}\text { D5 } \\
\text { D9 }\end{array}$ & $\begin{array}{l}L \\
R\end{array}$ & $\begin{array}{l}1 \\
1\end{array}$ & $\begin{array}{l}1 \\
1\end{array}$ & $\begin{array}{l}\text { Segmented } \\
\text { Segmented }\end{array}$ & Nil & Nil \\
\hline 11 & 3 yr 5 mo & Male & $\begin{array}{l}\text { D10 } \\
\text { L3 }\end{array}$ & $\begin{array}{l}R \\
L\end{array}$ & $\begin{array}{l}1 \\
1\end{array}$ & $\begin{array}{l}1 \\
1\end{array}$ & $\begin{array}{l}\text { Segmented } \\
\text { Segmented }\end{array}$ & $\begin{array}{l}\text { Tetrology of fallot } \\
\text { (operated } 1 \text { mo } \\
\text { after birth) }\end{array}$ & Nil \\
\hline 12 & 13 yr 8 mo & Female & $\mathrm{L} 3,4$ & L & 2 & I & Semi segmented & Nil & Nil \\
\hline 13 & 13 yr 3 mo & Female & $\mathrm{D} 12$ & L & 1 & 1 & Segmented & Nil & Nil \\
\hline 14 & 24 yr 10 mo & Male & L4 & L & 1 & 1 & Semisegmented & Nil & Nil \\
\hline 15 & 7 yr 7 mo & Female & $\mathrm{L} 2,3,4$ & L & 3 & IV & $\begin{array}{l}\text { Multiple failure of } \\
\text { formation and } \\
\text { segmentation failure }\end{array}$ & Nil & Nil \\
\hline 16 & 11 yr 3 mo & Male & L3 & $\mathrm{R}$ & 1 & 1 & Segmented & Nil & Nil \\
\hline 17 & $24 \mathrm{yr}$ & Female & L1 & R & 1 & 1 & Segmented & Nil & Nil \\
\hline 18 & $4 \mathrm{yr}$ & Female & L1 & $\mathrm{R}$ & 1 & 1 & Semisegmented & Nil & Nil \\
\hline 19 & 9 yr 6 mo & Male & D11,D12 & $\mathrm{R}$ & 2 & 1 & Segmented & Nil & Nil \\
\hline 20 & $16 \mathrm{yr}$ & Female & $\mathrm{D} 12$ & $\mathrm{R}$ & 1 & III & $\begin{array}{l}\text { Segmented with } \\
\text { concave bar }\end{array}$ & Nil & Nil \\
\hline 21 & $16 \mathrm{yr}$ & Female & L5 & $\mathrm{R}$ & 1 & 1 & Semisegmented & Nil & Nil \\
\hline 22 & $16 \mathrm{yr}$ & Female & L1 & L & 1 & 1 & Semisegmented & Nil & Nil \\
\hline Mean & 11 yr 3 mo & - & - & - & 1.59 & - & - & - & - \\
\hline
\end{tabular}

planes was achieved in thoracolumbar vertebrae as compared to the thoracic and lumbar areas (Table 2). This difference was not statistically significant. Among the single versus multilevel procedures the maximum correction (percentage) was achieved in three level hemivertebra excision (Figs. 3,4$)$ in the sagittal $(p=0.9)$ and two level hemivertebra excision in the coronal plane $(p=0.740)$. The difference in loss of coronal correction was not statistically significant when compared to single level. The loss of sagittal correction was significant in the two-level excision 

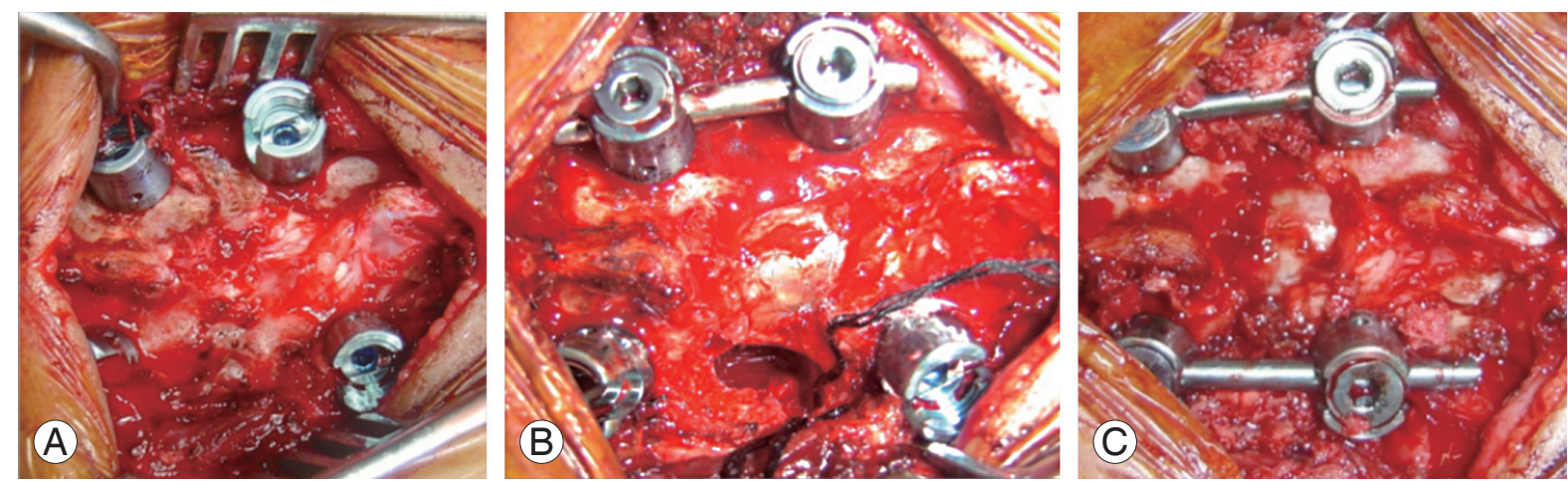

Fig. 1. Intraoperative pictures of a 2-year 4-month old patient who had single level hemivertebra. (A) Insertion of pedicle screws. (B) Posterior hemivertebrectomy. (C) Correction achieved by gradual compression.

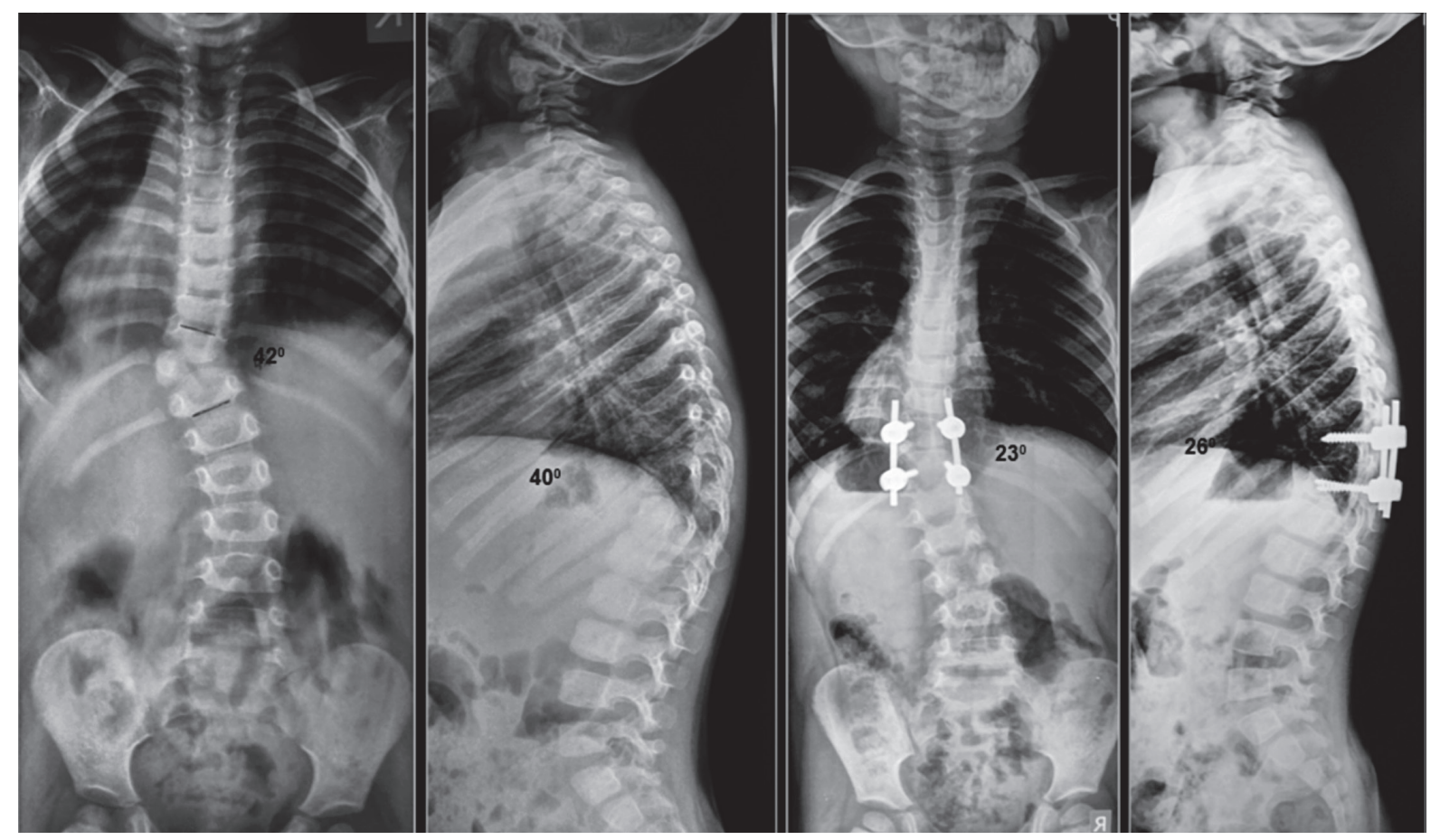

Fig. 2. Standing preoperative and one-year postoperative skiagrams of the patient presented in Fig 1.

Table 2. Distribution of results based on the site of hemivertebra(e)

\begin{tabular}{|c|c|c|c|c|c|c|c|c|}
\hline \multirow{2}{*}{$\begin{array}{l}\text { Hemivertebrae } \\
\text { location }\end{array}$} & \multicolumn{2}{|c|}{$\begin{array}{l}\text { Sagittal correction } \\
\text { achieved (postop) }\end{array}$} & \multicolumn{2}{|c|}{$\begin{array}{l}\text { Coronal correction } \\
\text { achieved (postop) }\end{array}$} & \multicolumn{2}{|c|}{$\begin{array}{l}\text { Sagittal correction lost } \\
\text { at final follow-up }\end{array}$} & \multicolumn{2}{|c|}{$\begin{array}{l}\text { Coronal correction } \\
\text { lost at final follow-up }\end{array}$} \\
\hline & Degree & Percentage & Degree & Percentage & Degree & Percentage & Degree & Percentage \\
\hline Thoracic (D1-10) & 14 & 34.7 & 24.4 & 40.9 & 0.7 & 2.2 & 3 & 4.6 \\
\hline $\begin{array}{l}\text { Thoracolumbar } \\
\text { (D11-L1) }\end{array}$ & 27.6 & 75.8 & 28.0 & 62.4 & 1.4 & 4.6 & 1.3 & 3.3 \\
\hline Lumbar (L2-L5) & 15.1 & 47.3 & 19.6 & 49.7 & 1.6 & 3.6 & 1.8 & 5.1 \\
\hline
\end{tabular}

Postop, postoperative. 

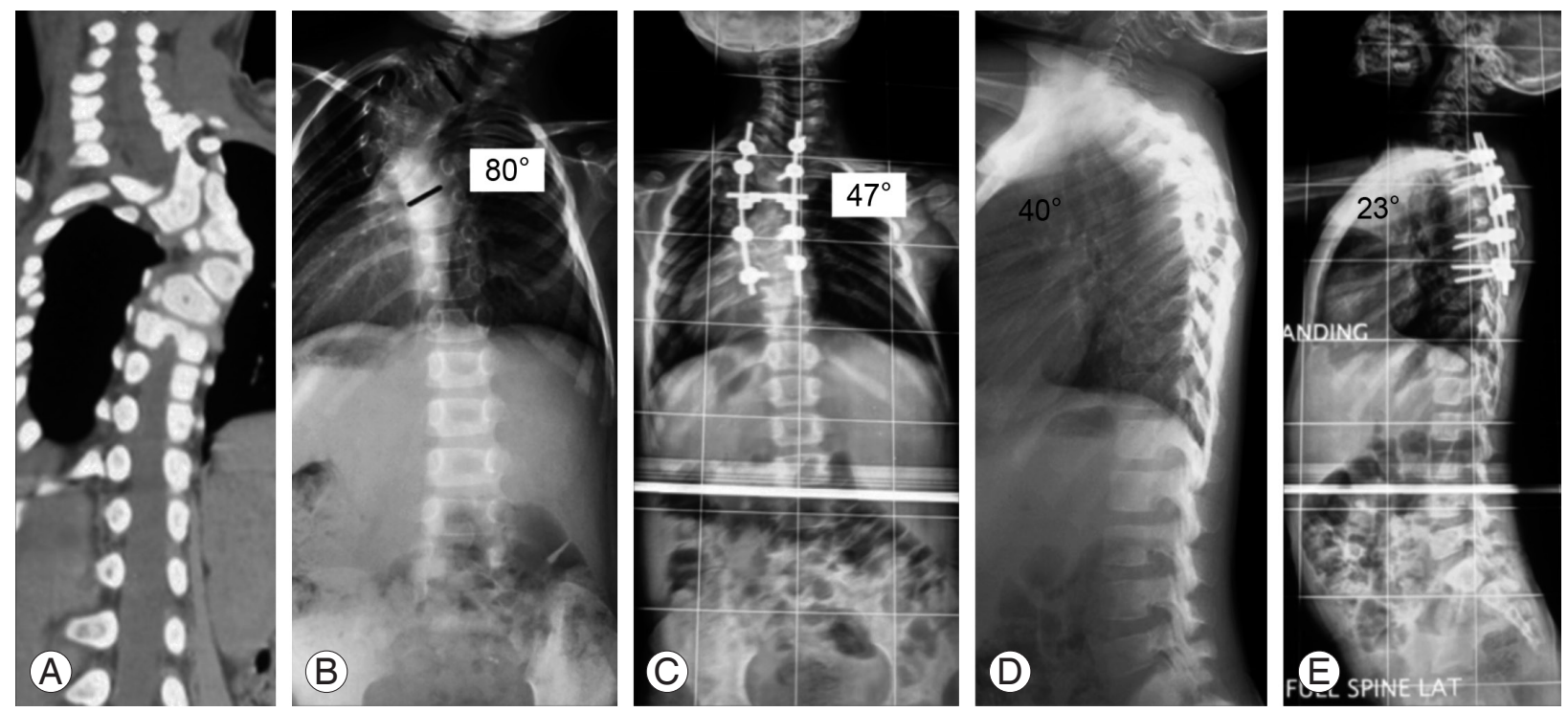

Fig. 3. Radiological images of a 4-year-old female patient. (A) Coronal reconstruction computed tomography showing three level hemivertebrae. (B, C) Preoperative and 2.5-year postoperative anterior-posterior whole spine X-rays. (D, E) Preoperative and 2.5-year follow-up lateral whole spine skiagrams.

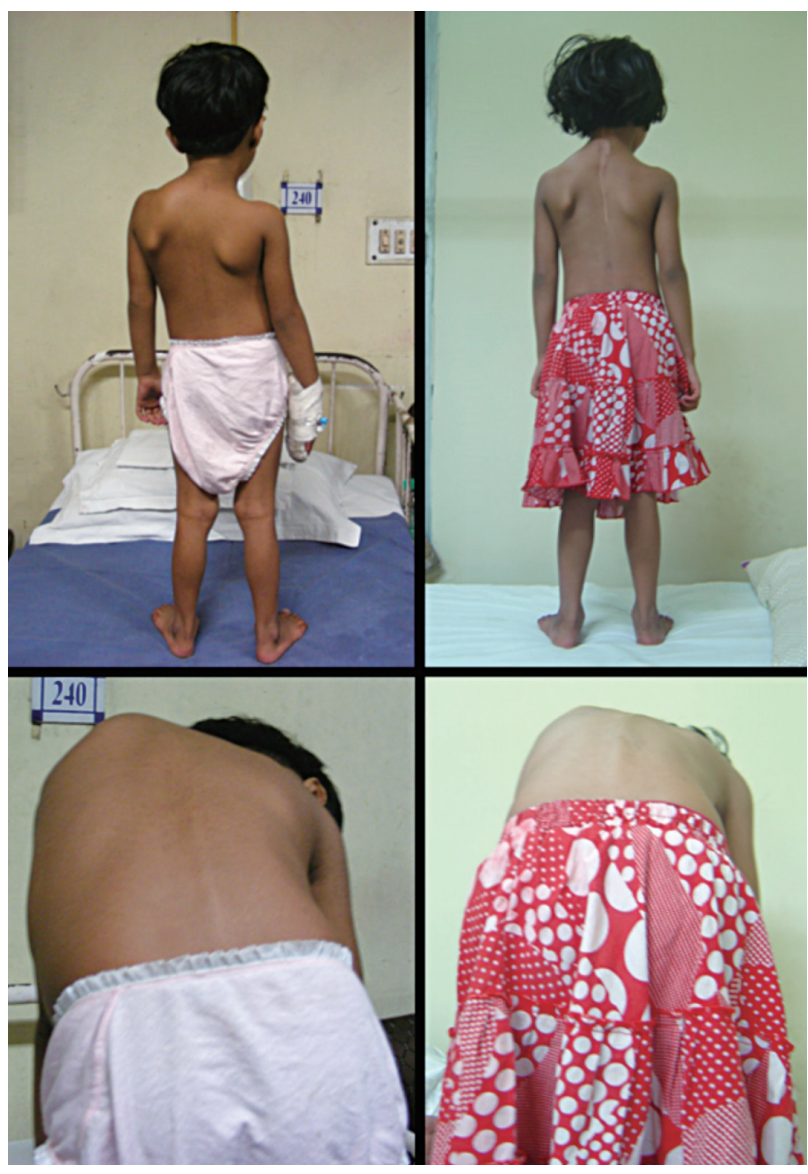

Fig. 4. Preoperative and 2.5-year follow-up clinical photographs of same patient described in Fig. 3. Note the improvement in shoulder level and rib hump. but not in the three-level excision (Table 3).

\section{Complications}

There were two instances of significant intraoperative signal changes on neurophysiological monitoring. Significantly decreased intraoperative neurophysiological monitoring signals in both lower limbs (>50\% drop of motor evoked potential) were recorded after scoliosis correction in one case. The correction was reversed by loosening the construct; the mean arterial pressure was raised and depth of anaesthesia was lowered. The signals regained and the deformity was then corrected gradually in a more controlled and graded manner. There was no neurological deficit postoperatively. In the second patient, neurological monitoring showed a signal decrease to $30 \%$ of baseline MEP in the right quadriceps. The signal recovered to $90 \%$ of baseline by reversing the correction. The patient postoperatively had right quadriceps weakness (grade 4/5 medical research council). The weakness recovered completely in 6 weeks. One patient (4.5\%) had to be revised for screw cut-out and loss of correction.

The neurology of the patients remained unaltered during the follow-up period. All patients had achieved fusion at one-year follow-up. 
Table 3. Distribution of results based on number of hemivertebra(e) removed

\begin{tabular}{|c|c|c|c|c|c|c|c|c|}
\hline \multirow{2}{*}{$\begin{array}{l}\text { No. of } \\
\text { hemivertebrae }\end{array}$} & \multicolumn{2}{|c|}{$\begin{array}{l}\text { Sagittal correction } \\
\text { achieved (postop) }\end{array}$} & \multicolumn{2}{|c|}{$\begin{array}{l}\text { Coronal correction } \\
\text { achieved (postop) }\end{array}$} & \multicolumn{2}{|c|}{$\begin{array}{l}\text { Sagittal correction lost } \\
\text { at final follow-up }\end{array}$} & \multicolumn{2}{|c|}{$\begin{array}{l}\text { Coronal correction } \\
\text { lost at final follow-up }\end{array}$} \\
\hline & Degree & Percentage & Degree & Percentage & Degree & Percentage & Degree & Percentage \\
\hline 1 & 16.6 & 52.6 & 21.29 & 48.23 & 0.38 & 1.50 & 1.4 & 3.4 \\
\hline 2 & 20.6 & 50.1 & 32.2 & 54.2 & 3.8 & $11.5(p<0.05)$ & 3.8 & $6.0(p=0.30)$ \\
\hline 3 & 23.0 & 53.3 & 27 & 52.9 & 1.6 & $3.3(p=0.45)$ & 3.3 & $7.5(p=0.16)$ \\
\hline
\end{tabular}

Postop, postoperative.

\section{Discussion}

All studies focussing on the congenital scoliosis have clearly pointed out that without treatment the outcome usually is unacceptable [8]. Of the untreated cases, only $10 \%$ have a curve of $\leq 20^{\circ}$ - and $64 \%$ have curves that are greater than 40 degrees [1]. With increasing time, the deformities become more structural and maximum corgrection is achieved when the patient is operated on early (preferably before 5 years) [9]. In our series the mean age was 11.2 years with only seven patients $(31.8 \%)<5$ years of age. The mean sagittal (59.8\% vs. $35.1 \%, p=0.03)$ and coronal $(56.2 \%$ vs. $40.3 \%, p=0.02)$ correction was achieved in patients $>5$ years of age. This could be because five of seven of the patients $<5$ years of age had hemivertebrae present in the dorsal spine, where correction is difficult to achieve because of crowding and deformity of the ribs.

Posterior fusion is the simplest method in which the spine was fused from endvertebra to end-vertebra of the curve, posteriorly. Winter reported the bending of fusion mass posteriorly causing worsening in about $14 \%$ of cases [2]. Kesling et al. [10] reported a value of $15 \%$. Hall et al. [11] reported that addition of Harrington instrumentation was a solution, allowing maintenance of the reduction achieved at the operative table as compared to postoperative casting, as well as reducing the incidence of pseudoarthosis.

The first excision of a hemivertebra from the front was performed in 1928 by Royle [12], followed later by Compere [13] and Von Lackum and Smith [14] in the lumbar spine. Wiles [15] performed thoracic spine surgery using a posterolateral approach by resecting ribs in two children but the patients developed kyphosis. Excision of the hemivertebrae as a two-stage procedure became popular $[16,17]$. Bradford and Boachie-Adje [7] reported that the procedure can be done in a single stage. They described the procedure in seven patients who were treated with a single-stage anterior and posterior arthrodesis; approximately $70 \%$ correction was achieved after an average follow-up of 45.6 months. Kokubun et al. [18] and Leatherman [19] also reported single-stage anterior-posterior hemivertebrectomy as a safe and efficacious procedure.

However, the morbidity and complications of the anterior approach remain concerns. Wang et al. [20] retrospectively analysed 60 patients divided equally in single-stage anterior-posterior and posterior only group and analysed them with respect to operation time, blood loss, degree of correction of the main curve/segmental curve/ kyphosis, average hospital stay, and complications. Mean operation time, blood loss, and hospital stay were significantly less in the posterior only group. The average correction rate of the main curve/segmental curve/kyphosis of the anteriorposterior group was marginally better $(p>0.05)$. However, the author reported a complication rate of $6.7 \%$ in the former group vs. $10 \%$ in the posterior group ( $p>0.05$ ), of which two-thirds were radiculopathies. We did not have any permanent nerve/cord injury because all the cases were done under intraoperative neurophysiological monitoring.

Shono et al. [21] retrospectively studied 12 patients 8 to 24 years of age with congenital kyphoscoliosis caused by a single hemivertebra. Preoperative scoliosis and kyphosis averaging $49^{\circ}$ and $40^{\circ}$ was corrected to $18^{\circ}$ and $17^{\circ}$, respectively. The author concluded that single-stage posterior hemivertebrectomy is safe and effective in structural kyphoscoliotic deformity caused by a thoracic or thoracolumbar single hemivertebra. In our series, the maximum correction immediate postoperatively in both sagittal and coronal planes was achieved in thoracolumbar hemivertebrae followed by lumbar hemivertebrae followed by 
thoracic hemivertebrae. Correction was maintained at the last follow-up. This is attributable to the fact that in the thoracic region the deformity correction is resisted by the presence of deformed ribs and chest wall, whereas in the lumbar region the vertebrae are bigger and the ligaments are stronger, and so are able to resist correction. The thoracolumbar junction being a transition zone has floating ribs and relatively smaller vertebrae and weaker ligaments.

In a multi-center trial, Yaszay et al. [22] compared three modalities: hemiepiphysiodesis or in situ fusion, instrumented fusion without hemivertebra excision, and instrumented hemivertebra excision. The conclusion was that posterior hemivertebra resection in younger patients resulted in better percent correction than the other two techniques, although it also was associated with higher complication rate. However, despite some of its limitations posterior resection of hemivertebrae with transpedicular instrumentation is a safe and promising procedure [23]. Using a posterior-only approach we were able to correct deformity caused by hemivertebra at the single, two, and three levels. The deformity correction was maximum in three-level hemivertebrectomy in both the sagittal and coronal planes (Table 3).

The pedicle screw instrumentation quite safe in juvenile and adolescents [24,25]. Harimaya et al. [26] reported 99\% accuracy of pedicle screw placement in juvenile and children with no intraoperative or short-term screw-related complications. We did not have any implant related complications in our series.

\section{Conclusions}

Posterior hemivertebrectomy is a safe and effective procedure for congenital scoliosis. Single, two, and three-level hemivertebrae can be safely removed with good correction of deformity.

\section{Conflict of Interest}

No potential conflict of interest relevant to this article was reported.

\section{References}

1. McMaster MJ, Ohtsuka K. The natural history of congenital scoliosis: a study of two hundred and fiftyone patients. J Bone Joint Surg Am 1982;64:1128-47.
2. Winter RB, Moe JH, Lonstein JE. Posterior spinal arthrodesis for congenital scoliosis: an analysis of the cases of two hundred and ninety patients, five to nineteen years old. J Bone Joint Surg Am 1984;66: 1188-97.

3. Winter RB, Moe JH, Eilers VE. Congenital scoliosis a study of 234 patients treated and untreated. J Bone Joint Surg Am 1968;50:1-15.

4. Winter RB, Moe JH, Wang JF. Congenital kyphosis. Its natural history and treatment as observed in a study of one hundred and thirty patients. J Bone Joint Surg Am 1973;55:223-56.

5. McMaster MJ, Singh H. Natural history of congenital kyphosis and kyphoscoliosis: a study of one hundred and twelve patients. J Bone Joint Surg Am 1999;81: 1367-83.

6. Bergoin M, Bollini G, Taibi L, Cohen G. Excision of hemivertebrae in children with congenital scoliosis. Ital J Orthop Traumatol 1986;12:179-84.

7. Bradford DS, Boachie-Adjei O. One-stage anterior and posterior hemivertebral resection and arthrodesis for congenital scoliosis. J Bone Joint Surg Am 1990;72:536-40.

8. Nasca RJ, Stilling FH 3rd, Stell HH. Progression of congenital scoliosis due to hemivertebrae and hemivertebrae with bars. J Bone Joint Surg Am 1975;57: 456-66.

9. Marks DS, Sayampanathan SR, Thompson AG, Piggott H. Long-term results of convex epiphysiodesis for congenital scoliosis. Eur Spine J 1995;4:296-301.

10. Kesling KL, Lonstein JE, Denis F, et al. The crankshaft phenomenon after posterior spinal arthrodesis for congenital scoliosis: a review of 54 patients. Spine (Phila Pa 1976) 2003;28:267-71.

11. Hall JE, Herndon WA, Levine CR. Surgical treatment of congenital scoliosis with or without Harrington instrumentation. J Bone Joint Surg Am 1981;63:60819.

12. Royle ND. The operative removal of an accessory vertebra. Med J Aust 1928;1:467-8.

13. Compere EL. Excision of hemivertebrae for correction of congenital scoliosis. J Bone Joint Surg Am 1932;14: 555-62.

14. Von Lackum WH, Smith AD. Removal of vertebral bodies in the treatment of scoliosis. Surg Gynecol Obstet 1933;57:250-6.

15. Wiles P. Resection of dorsal vertebrae in congenital 
scoliosis. J Bone Joint Surg Am 1951;33:151-4.

16. Holte DC, Winter RB, Lonstein JE, Denis F. Excision of hemivertebrae and wedge resection in the treatment of congenital scoliosis. J Bone Joint Surg Am 1995;77:159-71.

17. Leatherman KD, Dickson RA. Two-stage corrective surgery for congenital deformities of the spine. J Bone Joint Surg Br 1979;61:324-8.

18. Kokubun S, Sakurai M, Rijial KP, et al. Operative technique of one-stage anterior and posterior excision of hemivertebra. J Jpn Scoliosis Soc 1991;6:193201.

19. Leatherman KD. The management of rigid spinal curves. Clin Orthop Relat Res 1973;(93):215-24.

20. Wang L, Song Y, Pei F, et al. Comparison of one-stage anteroposterior and posterior-alone hemivertebrae resection combined with posterior correction for hemivertebrae deformity. Indian J Orthop 2011;45: 492-9.

21. Shono Y, Abumi K, Kaneda K. One-stage posterior hemivertebra resection and correction using segmen- tal posterior instrumentation. Spine (Phila Pa 1976) 2001;26:752-7.

22. Yaszay B, O’Brien M, Shufflebarger HL, et al. Efficacy of hemivertebra resection for congenital scoliosis: a multicenter retrospective comparison of three surgical techniques. Spine (Phila Pa 1976) 2011;36:205260.

23. Ruf M, Harms J. Hemivertebra resection by a posterior approach: innovative operative technique and first results. Spine (Phila Pa 1976) 2002;27:1116-23.

24. Ruf M, Harms J. Pedicle screws in 1- and 2-year-old children: technique, complications, and effect on further growth. Spine (Phila Pa 1976) 2002;27:E460-6.

25. Ruf M, Harms J. Posterior hemivertebra resection with transpedicular instrumentation: early correction in children aged 1 to 6 years. Spine (Phila Pa 1976) 2003;28:2132-8.

26. Harimaya K, Lenke LG, Son-Hing JP, et al. Safety and accuracy of pedicle screws and constructs placed in infantile and juvenile patients. Spine (Phila Pa 1976) 2011;36:1645-51. 